\title{
Viral Monitoring and Prevalence of Viral Failure in HIV-1 Infected Children under First Line Antiretroviral Therapy during the First 60 Months of Treatment in Yaoundé, Cameroon: A Serial Cross Sectional Analysis
}

\author{
Anne Esther Njom Nlend*, Sidonie Lyeb, Suzie Tetang Ndiang Moyo, Annie Nga Motaze \\ National Social Insurance Fund Hospital, Department of Pediatrics, Cameroon \\ Email: *anne.njom@gmail.com \\ Received 6 December 2015; accepted 6 March 2016; published 9 March 2016 \\ Copyright (C) 2016 by authors and Scientific Research Publishing Inc. \\ This work is licensed under the Creative Commons Attribution International License (CC BY). \\ http://creativecommons.org/licenses/by/4.0/

(c) (i) Open Access

\begin{abstract}
Objective: The objective was to measure the prevalence of viral failure (VF) in HIV-1-infected children on first-line antiretroviral therapy (ART) in routine practice. Methods: Serial cross sectional analysis of viral load (VL) in HIV-1 infected children on first-line ART for $\geq 24$ weeks was done. VL was measured by Real-Time-Polymerase chain reaction (biocentrics). Samples were collected at 6, 12, 24, 36, 48, 60 months of treatment. Main measurement: Virological failure (VF) defined by a one-off VL $>1000$ copies/ml. Results: 375 children aged $\leq 16$ years on first-line-ART were included. Median age at ART start was 4.2 years and $\geq \mathbf{5 0} \%$ have started ART $\leq 3^{\text {rd }}$ birthday. A total of 717 measurements of VL were collected. VF was rated between $18 \%$ and $26 \%$ from 6 - 60 months (mean 20.2\%), 95\% IC [13.1 - 27.3] at the threshold of 1000 copies/ml, not too different at the threshold of 400 copies $/ \mathrm{ml}, 21 \%$ - 30\% (mean $23.9 \%$ ), 95\% IC [16.3 - 31.5], p = 0.9. Conclusion: In Yaounde, almost $20 \%$ of children on first-line of adherent-ART can experiment VF while improving immune status urging improvement of adherence.
\end{abstract}

\section{Keywords}

HIV, Viral Failure, Antiretroviral Therapy, Children

\footnotetext{
${ }^{*}$ Corresponding author.

How to cite this paper: Nlend, A.E.N., Lyeb, S., Moyo, S.T.N. and Motaze, A.N. (2016) Viral Monitoring and Prevalence of Viral Failure in HIV-1 Infected Children under First Line Antiretroviral Therapy during the First 60 Months of Treatment in Yaoundé, Cameroon: A Serial Cross Sectional Analysis. Open Journal of Pediatrics, 6, 69-74. http://dx.doi.org/10.4236/ojped.2016.61012
} 


\section{Introduction}

In 2013, Sub-Saharan Africa (SSA) was recording the highest burden of the HIV-1 epidemic, contributing for more than $90 \%$ in the new cases of perinatally acquired HIV pediatric infections [1]; and almost 656,000 children younger than 15 years were receiving antiretroviral therapy in low-and middle-income countries [2]. In Cameroon, nearly 5900 were reported to be on ART among the 39,000 HIV infected children eligible nationwide [3]. The benefits of ART on the improvement of survival and quality of life of HIV infected children have been widely demonstrated and the emerging concerns are focused around the long term outcome after ART initiation [4] [5]. In this sense, the issue of biological monitoring and permanent viral suppression is of utmost importance as second line regimens are few in SSA in case of treatment failure, thus making the challenge of a longest duration on first-line ART a sounding priority [5] [6]. Unfortunately apart from clinical follow-up, routine biological monitoring falls short in many SSA settings, though established as gold standard in western countries. The latest guidelines modified in 2013 make the measurement of viral load (VL) a key stone of the biological follow-up [5]. In Europe and in Asia, the benefits of ART coupled to closely monitoring have demonstrated good achievement in regards to viral suppression [7] [8]. On the other hand, few studies from SSA have reported on the prevalence rate of viral suppression/failure in children, in routine care. In Senegalese children under first line ART for a median time of 20 months, a 56\% rate of VF was recorded by Kebe et al. in West Africa [9]; similarly, a high rate of $61 \% \mathrm{VF}$ at the threshold of 400 copies/ml was found among 97 children on first line ART in Mali at 60 months of treatment [10]. In Cameroon unfortunately, few data are available on the topic, except a report from Fokam et al. involving our site with a 50\% VF at a median follow-up of 24 months [11]. In this context, we designed a study with the objective to measure the frequency of virological failure of HIV infected children after 24 weeks of first line adherent ART, in a single site, following the latest WHO recommendations.

\section{Methods}

\subsection{Study Design}

This was a descriptive, retrospective, serial cross sectional study nested in a cohort of HIV infected children on antiretroviral treatment.

Setting and population: The study site was the "Centre Hospitalier d'ESSOS" an approved centre for antiretroviral therapy in Yaoundé. Enrolment of children on ART treatment started in this centre in 2005. We included, children on triple first line antiretroviral therapy lasting for $\geq 6$ months. The children enrolled were extracted from an observational cohort of 450 children on ART. Inclusion criteria were being on first line ART and aged $\leq 16$ years. After exclusion of children on second line ART $(\mathrm{N}=75)$, we included 375 children who started ART between 2006 and 2009 and were followed-up for 60 months.

\subsection{Treatment Guidelines and Monitoring Procedures}

At the time of ART initiation in those children, the national guidelines applicable were recommending for first line of ART: Zidovudine (ZDV) or Stavudine (d4T) or Abacavir (ABC) + Lamivudine (3TC) and either Efavirenz (EFV) or Nevirapine (NVP) in children $<3$ years and $<10 \mathrm{~kg}$. Antiretroviral therapy was initiated under WHO evolving criteria taking into account advanced clinical stages or immunodeficiency. From 2006, the threshold of CD4 cell percentage levels for severe immunodeficiency was less than $25 \%$ for infants 11 months or less, $<20 \%$ for children aged 12 to 35 months, and $<15 \%$ for children 3 years or older. Pre-treatment viral load was not mandated prior to ART initiation.

\subsection{Monitoring Procedures}

Clinical procedures: During the first 3 months of treatment, HIV-infected children were seen monthly at the clinic for medical follow-up then quarterly. Adherence to medication was self reported at each visit and completed by subsequent individual adherence counseling sessions. Sessions of education and adherence counseling were given to both parents and children below 6 years; group counseling was reserved for both parents and/or preadolescents; home visits for counseling support were indicated in case of adherence failure.

Biological follow-up: At baseline, CD4 cell count was mandated while viral load measurement was recommended. CD4 cell count measurement done at the CHE laboratory using was expressed in absolute count and percentage; Children's serum samples were quantified for HIV-1 RNA load using real time reverse transcriptase 
PCR (Generic HIV viral load, Biocentrics). For all HIV infants treated, irrespective of clinical and immunological status, a measurement of CD4 cell count and viral load was prescribed after six months of ART and then yearly. All the samples for viral load were analyzed at the "Laboratoire Centre Pasteur" in Yaounde acting as service provider at a unit cost of 30US\$.

\subsection{Key Variables and Main Measurement}

Viral load values were expressed in copies/ml. In line with WHO 2013 guidelines; in this study, case definition of virological failure (VF) was a one-off measurement of viral load $\geq 1000 \mathrm{copies} / \mathrm{ml}$.

\subsection{Data Collection and Statistical Analysis}

For this analysis, data routinely collected during follow-up and stored in the patient files, were extracted and transferred in an excel sheet form. Statistical analysis was done using software $\mathrm{R}$ version 3.1.1. Continuous and categorical variables were summarized using medians and interquartile range (IQR) and proportions respectively. A confidence interval of $95 \%$ was considered as the margin for percentage accuracy.

\subsection{Ethics and Administrative Aspects}

This study received the ethical approval of the Institutional Review Board of the Centre Hospitalier d'ESSOS and the administrative authorization of the Hospital. Informed parental consent was obtained at the entry point of care. Partial support for payment of viral load was offered yearly to the patients followed-up as part of the routine management. Confidentiality and security were ensured in the treatment of all the files.

\section{Results}

\subsection{Demographic Characteristics of the Infants at ART Start}

We included 375 children in the analysis aged $\leq 16$ years, median, 9.5 years [IQR 7 - 13]. Sex ratio was 1.22/1 slightly favoring male. Median age at ART start was 4.2 years [IQR 1.2 - 6.5], however almost 1 in 2 (50\%) had started treatment before their third birthday. The median time of follow-up was 48 months. The median percentage of CD4 cell count at ART start was 13\% [IQR 7 - 20]. The pre-treatment value of viral load was assessed in a few number of children $(\mathrm{N}=130,34 \%)$ representing those who were able to support the cost of this biological test and was measured at 778,996 copies/ml IQR [252,983. 2,770,000]. The average number of measurement of viral load per child was 2.42 .

\subsection{Viral Load Monitoring in Children}

Table 1 shows the number of samples analyzed from 6 to 60 months according to the schedule. A total of 717 samples were collected. The coverage of viral measurement varies from $34 \%$ to $45 \%$ of children in follow-up at each point of collection. In addition, among them, $20.2 \%$ had no viral load recorded during the period of follow-up after ART initiation from 6 to 60 months; an exception was one single child who had been faithfully assessed at each point of follow-up.

\subsection{Percentage of Children Achieving Immune Restoration}

The average rate of CD4 cell count varies from $13 \%$ prior to ART initiation to $60 \%$ at 60 months of treatment. In children below 5 years, the percentage of children with CD4 cell count above $25 \%$ varies from $13 \%$ at the onset of treatment to $88 \%$ at 60 months of treatment. Similarly, among children older than 5 years, the rate of those having more than $350 / \mathrm{mm}^{3} \mathrm{CD} 4$ cell, ranges $38 \%$ at the onset of treatment to $90 \%$ at 60 months post ART initiation (Table 2).

\subsection{Viral failure}

Overall 148/717 samples show a viral load above 1000 copies/ml. VF was rated between $18 \%$ to $26 \%$ from 6 60 months (mean 20.6\%), 95\% IC [13.1- 27.3] at the threshold of 1000 copies $/ \mathrm{ml}$ not too different at the threshold of 400 copies/ml, 21\% - 30\% (mean 23.9\%), 95\% IC [16.3 - 31.5], p = 0.9. Figure 1 resumes the distribu- 
Table 1. Number and rate of HIV infected children under first line antiretroviral therapy (ART) in Yaounde assessed for viral load measurement at each point of biological follow-up from 6 to 60 months post ART.

\begin{tabular}{cccccccc}
\hline & $\mathbf{6}$ months & $\mathbf{1 2}$ months & $\mathbf{2 4}$ months & $\mathbf{3 6}$ months & $\mathbf{4 8}$ months & $\mathbf{6 0}$ months \\
\hline Number children & 375 & 359 & 317 & 300 & 208 & 146 \\
number assessed & 155 & 123 & 149 & 132 & 95 & 63 \\
\% & 41.3 & 34.3 & 47.0 & 44.0 & 45.7 & 43.2 \\
\hline
\end{tabular}

Table 2. Evolving rate of HIV infected children having a good level of CD4 cell count (absolute or \%) from 6 to 60 months post ART initiation in Centre Hospitalier d'ESSOS.

\begin{tabular}{ccccccccc} 
& pretreatment & $\mathbf{6}$ months & $\mathbf{1 2}$ months & $\mathbf{1 8}$ months & $\mathbf{2 4}$ months & $\mathbf{3 6}$ months & $\mathbf{4 8}$ months & $\mathbf{6 0}$ months \\
\hline$\% \geq \mathbf{2 5 \%}(\mathbf{N}=\mathbf{1 3 4})$ & 13 & 47 & 50 & 58 & 59 & 74 & 74 \\
$\mathbf{\%} \geq \mathbf{3 5 0} \mathbf{N}=\mathbf{1 4 9}$ & 38 & 73 & 79 & 85 & 94 & 86 & 88 \\
\hline
\end{tabular}

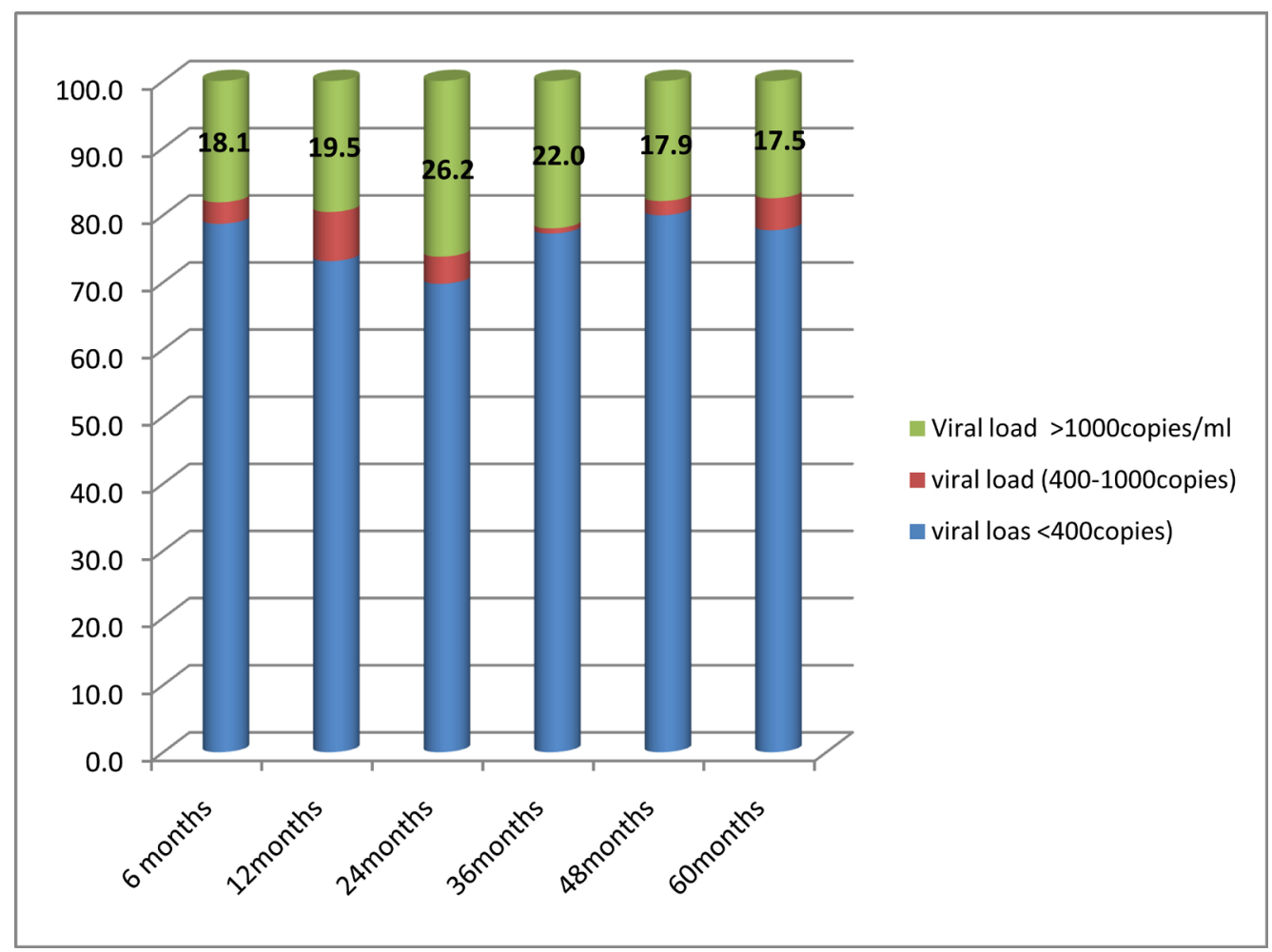

Figure 1. Percentage of viral load above 1000 copies/ml in children under first line antiretroviral therapy in Yaounde from 6 to 60 months of adherent treatment.

tion of the viral profile of HIV infected children on first line ART at each point of follow-up.

\section{Discussion}

First of all, in this report, we wish to outline the difficulties to monitor HIV infected children in routine practice in SSA, especially the hardness of routine VL testing in children. Our lost to biological follow-up (almost 20\% of children with no viral load) is imputable to the cost of HIV viral load tests and argues for the need to permanently subsidize such exams [12]. Despite those restrictions, our key finding was a VF of $20 \%$ to $25 \%$ (threshold of 400 copies $/ \mathrm{ml}$ ) at each point of monitoring during the first 60 months of ART in children at Yaoundé. This rate of VF posted in our centre is quite laudable, in comparison to previous data registered in SSA settings; in Tanzania, a rate of 51\% VF was recorded in children at median FU time of 24 months; similarly results reported from Senegal or Mali were worse [9] [10] [13]. Looking at other studies in SSA, our findings on immune resto- 
ration were consistent with previous reports despite a constant average rate of children on viral failure [14]-[16]. This observation of constant one-off rate of VF emphasizes the need of strengthening education and adherence counseling in HIV infected children at each contact, as almost 1 child in 5 was exposed to permanent VF in our centre. We are tempted to attribute our results to the routine practice of therapeutic education, anticipating that it may have helped achieving such low rate of VF in routine care settings [13] [17] [18]. Unfortunately in this report, we were limited to analyze the impact of therapeutic education on viral suppression, due to poor data collection of our process of adherence counseling, which was done at many points of care. In addition, this serial cross sectional study limited us in analyzing the proportion of children who frequently reverse from viral failure to suppression. These limitations suggest to design a prospective cohort study in order to measure the proportion of children with frequent rebound, as is known to cause damage and can favor the emergence of resistant viral strains. At last, in this descriptive study, we did not take into account the rate of adolescents though there are known to be more at risk of VF; a low proportion of adolescent can explain our relative low rate of VF in comparison to other settings [19]. Despite these findings, we keep in mind that $20 \%$ lost to viral follow-up is high and can mitigate our results thus, highlighting the need of further analysis.

\section{Conclusion}

In short, we found that HIV-1 RNA viral load stands above 1000 copies/ml in almost $20 \%$ of HIV infected children in Yaoundé, after 24 weeks or more of ART adherent treatment making improvement of adherence counseling mandated. To this step, our results emphasize the need to increase access to routine viral monitoring in all HIV infected children on ART in order to timely recognize virological failure, especially in children free of clinical and immune failure.

\section{Acknowledgements}

We gratefully acknowledge the children who participated in this study and all the supportive staff of the antiretroviral treatment center. Special mention of gratitude goes to the French Foundation GlaxoSmithKline for funding routine access to viral load for children under antiretroviral treatment.

\section{Conflicting Interests}

The authors declare that they have no conflicting interests.

\section{Authors' Contributions}

AENN, LS, STN, NA designed the study and collected data. AENN carried out the analysis and drafted the manuscript. All authors reviewed the manuscript and read the final version.

\section{References}

[1] (2013) Report on the HIV Epidemic. UNAIDS, Geneva.

[2] http://www.childinfo.org/

[3] (2010) National Report on HIV and AIDS Program. Ministry of Public Health, Cameroon.

[4] Antiretroviral Therapy of HIV Infection in Infants and Children: Towards Universal Access: Recommendations for a Public Health Approach-World Health Organization 2010.

[5] (2013) Consolidated Guidelines on the Use of Antiretroviral Drugs for Treating and Preventing HIV Infection. World Health Organization, Geneva.

[6] Oliveira, R., Krauss, M., Essama-Bibi, S., et al. (2010) Viral Load Predicts New World Health Organization Stage 3 and 4 Events in HIV-Infected Children Receiving Highly Active Antiretroviral Therapy, Independent of CD4 T Lymphocyte Value. Clinical Infectious Diseases, 51, 1325-1333. http://dx.doi.org/10.1086/657119

[7] Sutcliffe, C.G., van Dijk, J.H., Bolton, C., Persaud, D. and Moss, W.J. (2008) Effectiveness of Antiretroviral Therapy among HIV-Infected Children in Sub-Saharan Africa. The Lancet Infectious Diseases, 8, 477-489. http://dx.doi.org/10.1016/S1473-3099(08)70180-4

[8] Duong, T., Judd, A., Collins, I.J., Doerholt, K., Lyall, H., Foster, C., et al. (2014) Collaborative HIV Paediatric Study Steering Committee. Long-Term Virological Outcome in Children on Antiretroviral Therapy in the UK and Ireland. 
AIDS, 28, 2395-2405. http://dx.doi.org/10.1097/QAD.0000000000000438

[9] Kebe, K., Thiam, M., Diagne Gueye, N.R., Diop, H., Dia, A., et al. (2013) High Rate of Antiretroviral Drug Resistance Mutations in HIV Type 1-Infected Senegalese Children in Virological Failure on First-Line Treatment According to the World Health Organization Guidelines. AIDS Research and Human Retroviruses, 29, 242-249.

[10] Germanaud, D., Derache, A., Traore, M., et al. (2010) Level of Viral Load and Antiretroviral Resistance after 6 Months of Non-Nucleoside Reverse Transcriptase Inhibitor First-Line Treatment in HIV-1-Infected Children in Mali. Journal of Antimicrobial Chemotherapy, 65, 118-124. http://dx.doi.org/10.1093/jac/dkp412

[11] Fokam, J., Salpini, R., Santoro, M.C., Cento, V., Perno, C.F., Colizzi, V., et al. (2011) Drug Resistance among DrugNaive and First-Line Antiretroviral Treatment-Failing Children in Cameroon. Pediatric Infectious Disease Journal, 30, 1062-1068.

[12] Jobanputra, K., Parker, L.A., Azih, C., Okello, V., Maphalala, G., Jouquet, G., et al. (2014) Impact and Programmatic Implications of Routine Viral Load Monitoring in Swaziland. Journal of Acquired Immune Deficiency Syndromes, 67, 45-51. http://dx.doi.org/10.1097/QAI.0000000000000224

[13] Van Dijk, J.H., Sutcliffe, C.G., Munsanje, B., Sinywimaanzi, P., Hamangaba, F., Thuma, P.E., et al. (2011) HIV-Infected Children in Rural Zambia Achieve Good Immunologic and Virologic Outcomes Two Years after Initiating Antiretroviral Therapy. PLoS ONE, 6, e19006. http://dx.doi.org/10.1371/journal.pone.0019006

[14] Bolton-Moore, C., Mubiana-Mbewe, M., Cantrell, R.A., Chintu, N., Stringer, E.M., Chi, B.H., et al. (2007) Clinical Outcomes and CD4 Cell Response in Children Receiving Antiretroviral Therapy at Primary Health Care Facilities in Zambia. JAMA, 298, 1888-1899. http://dx.doi.org/10.1001/jama.298.16.1888

[15] Mgelea, E.M., Kisenge, R. and Aboud, S. (2014) Detecting Virological Failure in HIV-Infected Tanzanian Children. South African Medical Journal, 104, 696-699. http://dx.doi.org/10.7196/samj.7807

[16] Pham, H., Ishizaki, A., Nguyen, L., Phan, C., Phung, T., Takemoto, K., Pham, A., Bi, X., Khu, D. and Ichimura, H. (2014) Two-Year Outcome of First-Line Antiretroviral Therapy among HIV-1 Vertically Infected Children in Hanoi, Vietnam. International Journal of STD \& AIDS, pii: 0956462414556328.

[17] Tukei, V.J., Murungi, M., Asiimwe, A.R., Migisha, D., Maganda, A., Bakeera-Kitaka, S., Kalyesubula, I., Musoke, P. and Kekitiinwa, A. (2013) Virologic, Immunologic and Clinical Response of Infants to Antiretroviral Therapy in Kampala, Uganda. BMC Pediatrics, 13, 42. http://dx.doi.org/10.1186/1471-2431-13-42

[18] Childs, T., Shingadia, D., Goodall, R., Doerholt, K., Lyall, H., Duong, T., et al. (2015) CHIPS Steering Committee. Outcomes after Viral Load Rebound on First-Line Antiretroviral Treatment in Children with HIV in the UK and Ireland: An Observational Cohort Study. The Lancet HIV, 2, e151-e158. http://dx.doi.org/10.1016/S2352-3018(15)00021-1

[19] Kahana, S.Y., Fernandez, M.I., Wilson, P.A., Bauermeister, J.A., Lee, S., Wilson, C.M., et al. (2015) Rates and Correlates of Antiretroviral Therapy Use and Virologic Suppression among Perinatally and Behaviorally HIV-Infected Youth Linked to Care in the United States. Journal of Acquired Immune Deficiency Syndromes, 68, 169-177. http://dx.doi.org/10.1097/QAI.0000000000000408 